\title{
MATERIAL DIDÁTICO DIGITAL NA EDUCAÇÃO A DISTÂNCIA: PERCEPÇÃO DOS ACADÊMICOS DE MCP DA UNESC
}

\section{DIGITAL DIDACTIC MATERIAL IN DISTANCE EDUCATION: PERCEPTION OF UNESC MCP ACADEMICS}

\author{
Kamila Machado Pinheiro Silveira ${ }^{1}$ \\ Graziela Fátima Giacomazzo $^{2}$
}

\begin{abstract}
RESUMO: Este trabalho apresenta um estudo sobre Material Didático Digital (MDD) para Educação a Distância (EaD). O objetivo geral deste projeto foi verificar as percepções dos acadêmicos da disciplina de MCP sobre os materiais didáticos digitais (MDD). Para tanto, os objetivos específicos são: Pesquisar a história da educação a distância no Brasil e seus marcos significativos; Perceber a importância da construção do material didático para o processo de ensino aprendizagem; Verificar quais são os materiais digitais disponíveis na disciplina de MCP - Metodologia Científica e da Pesquisa; Verificar, a partir de uma seleção de materiais, a percepção dos acadêmicos e suas preferências. Para a fundamentação teórica desta pesquisa e pela ordem cronológica foram utilizados os seguintes autores: Ludke (1986), Neto (2003), Oliveira (2003), Alves (2009) e Behar (2013). Metodologicamente trata-se de uma pesquisa de natureza quanti-qualitativa, tendo como sujeitos os acadêmicos de MCP de 2019/01 da UNESC. Para a coleta de dados utilizou-se um questionário on-line. Foi possível concluir que os materiais são suficientes e apresentam características na sua elaboração que colaboram de forma significativa com a aprendizagem dos conteúdos da disciplina.
\end{abstract}

PALAVRAS-CHAVE: Material Didático. Educação a Distância. Metodologia Científica e da Pesquisa.

ABSTRACT: This study presents a study on Digital Didactic Material (MDD) for Distance Education $(\mathrm{EaD})$. The general objective of this project was to verify the perceptions of MCP students on digital didactic materials (MDD). To do so, the specific objectives are: To search the history of distance education in Brazil and its significant milestones; To realize the importance of the construction of didactic material for the learning teaching process; Check what digital materials are available in the subject of MCP - Scientific Methodology and Research; To verify, from a selection of materials, the perception of the students and their preferences. For the theoretical basis of this research and the chronological order, the following authors were used: Ludke (1986), Neto (2003), Oliveira (2003), Alves (2009) and Behar (2013).

\footnotetext{
${ }^{1}$ Graduada em Pedagogia/kamilamachadops@gmail.com

${ }^{2}$ Professora Doutora na Universidade do Extremo Sul Catarinense/ Docente PPGE - Mestrado e Doutorado/ Coordenadora do Setor de Educação a Distância/ Líder GP Interdisciplinar em Educação e Cultura Digital (EducDigital) /Pesquisadora no GP Inovação \& Avaliação (UFRGS). gfg@ unesc.net
}

Saberes Pedagógicos, Criciúma, v. 5, n¹, janeiro/abril 2021. - Curso de Pedagogia - UNESC 


\section{SABERES PEDAGÓGICOS \\ Revista do Curso de Graduaçào de Pedagogia - Unesc \\ ISSN 2526-4559}

Methodologically, this is a quantitative-qualitative research, having as subjects the 2019/01 MCP academic of UNESC. An online questionnaire was used to collect data. It was possible to conclude that the materials are sufficient and have characteristics in their elaboration that collaborate in a significant way with the learning of the contents of the discipline.

KEYWORDS: Didactic material. Distance Education. Scientific Methodology and Research.

\section{INTRODUÇÃO}

O presente trabalho discute a temática acerca dos Materiais Didáticos Digitais que são utilizados na modalidade de ensino a distância. Contudo, esta análise surgiu a partir da participação como bolsista do programa de iniciação científica do Artigo 170 (PIC170) da Universidade sob orientação da professora coordenadora do Setor de Educação a Distância (SEAD) da Universidade do Extremo Sul Catarinense (UNESC). A partir destas interações surgiu a curiosidade em investigar a percepção dos acadêmicos na disciplina a distância de Metodologia Científica da Pesquisa - MCP, trata-se de uma disciplina institucional que ocorre nesta modalidade de ensino desde 2017/01.

Dessa forma, quando nos referirmos a materiais digitais, pensamos em conteúdos que serão propostos para alunos da modalidade de Ensino a Distância. Esses materiais são o objeto deste estudo, pois quando são bem planejados, elaborados e estruturados tornam-se instrumentos que estimulam a aprendizagem significativa. Com isso, e como destaca Behar (2013, p. 237):

O material educacional digital (MED) é conceituado [...] como todo o material voltado à aprendizagem significativa e que utiliza um ou mais recursos digitais na sua elaboração. O termo é utilizado quando não há a necessidade de especificar a natureza do material e ao mesmo tempo abrangendo todas elas.

De acordo com Behar (2013, p. 239) algumas dessas práticas, por exemplo, são o conhecimento, a aprendizagem e, além disso, saber aplicar o seu conhecimento conquistado por este objeto de estudo oferecido. Contudo, é de grande relevância destacar o assunto sobre Materiais Didáticos Digitais dentro do campo institucional, por ser um processo de ensinoaprendizagem. A partir deste contexto, elaborou-se o seguinte problema de pesquisa: Quais as

Saberes Pedagógicos, Criciúma, v. 5, nº1, janeiro/abril 2021. - Curso de Pedagogia - UNESC 


\section{SABERES PEDAGÓGICOS \\ Revista do Curso de Graduaçào de Pedagogia - Unesc \\ ISSN 2526-4559

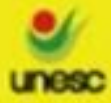

percepções dos acadêmicos da disciplina de MCP sobre os materiais didáticos digitais (MDD) para a aprendizagem dos conteúdos da disciplina?

O objetivo geral deste projeto foi verificar as percepções dos acadêmicos da disciplina de MCP sobre os materiais didáticos digitais (MDD). Para tanto, os objetivos específicos são: Pesquisar a história da educação a distância no Brasil e seus marcos significativos; Perceber a importância da construção do material didático para o processo de ensino aprendizagem; Verificar quais são os materiais digitais disponíveis na disciplina de MCP - Metodologia Científica e da Pesquisa; Verificar, a partir de uma seleção de materiais, a percepção dos acadêmicos e suas preferências.

Este trabalho se organiza a partir desta introdução, posteriormente apresenta-se brevemente a história e a trajetória da Educação a Distância, conceitua-se material didático trazendo especificamente para a disciplina de MCP da UNESC. Na sequência são descritos os procedimentos metodológicos, a análise dos dados e por fim a conclusão.

\section{EDUCAÇÃO A DISTÂNCIA: HISTÓRIAS E TRAJETÓRIAS}

Durante a sua trajetória, a Educação a Distância $(\mathrm{EaD})$ foi vista como uma forma educacional ainda muito desconsiderada no Brasil. Com isso, e de acordo com Oliveira (2003), o desenvolvimento das Tecnologias de Informação e Comunicação (TICs) na atualidade tem impulsionado o crescimento da $\mathrm{EaD}$, e, além disso, ressignificado o conceito em relação a esta modalidade educacional. O que contribui com a fala de Alves (2008, p. 10) que a história da $\mathrm{EaD}$ no Brasil, de acordo com algumas pesquisas, bem como a pesquisa de jornais disponíveis na época como do "jornal do Brasil" mostram em seus documentários maneiras de estudar a distância. Essas pesquisas de jornais mostram que ainda antes de 1900 havia informações para o oferecimento de cursos profissionalizantes pelos correios. Tratava-se de cursos ofertados não por instituições de ensino, mas por profissionais/professores particulares.

Os cursos ofertados eram voltados para quem tivesse o interesse em trabalhar, pois eram direcionados para a área do comércio. Alves $(2008$, p. 10) destaca que este ensino era por correspondência, e que os materiais didáticos eram fornecidos via correio e a grande maioria principalmente utilizava-se das ferrovias como transporte.

Saberes Pedagógicos, Criciúma, v. 5, nº1, janeiro/abril 2021. - Curso de Pedagogia - UNESC 


\section{SABERES PEDAGÓGICOS}

Revista do Curso de Graduaçào de Pedagogia - Unesc

ISSN 2526-4559

Além disso, cabe frisar e comentar diferentes marcos significativos na história da $\mathrm{EaD}$, destacando a regulamentação de 1998 pelo decreto $\mathrm{n}^{\circ}$ 5.622, de 19 de dezembro de 2005 . Trata-se de uma modalidade de educação na qual a intervenção didático-pedagógica na metodologia dos processos ensino-aprendizagem se desenvolve com a utilização das TICs. Atividades estas promovidas com os estudantes e professores a fim de proporcionar meios educativos em diferentes espaços.

Para tanto, as TICs são recursos e instrumentos que estão à disposição do aluno e que podem ser considerados como inestimável avanço para a melhoria do processo de ensinoaprendizagem na Educação a Distância.

Diante disso, sendo o computador um dos instrumentos que fazem parte da Tecnologia Digital e de acordo com Behar (2013, p. 42) o computador é identificado em qualquer espaço seja social ou institucional assim possibilitando o sujeito a um ensino que ultrapassa os muros educacionais. Assim, estabelecendo momentos de aprendizagem quando usado com intuito ao ensino. Em outras palavras, além de autorizar o sujeito a compartilhar conhecimentos e informações, é um recurso que se encontra em todo e qualquer lugar. Este cenário reproduz um impacto referente à $\mathrm{EaD}$, trazendo um novo perfil dos estudantes. $\mathrm{O}$ que corrobora com a fala de Behar (2013, p. 54):

\footnotetext{
Ainda hoje em nível mundial e nacional utiliza-se todo o tipo de suporte para a realização dos processos educativos à distância. Esses suportes foram se incorporando às práticas ao longo da história de acordo com as características socioculturais e tecnológicas: material impresso, rádio, televisão, CD/DVD computador e internet.
}

Partindo deste pressuposto, no Brasil a internet acabou se tornando o recurso chave para o desenvolvimento da EaD. Porém, cabe destacar que, para Behar (2013, p. 44), cada instituição analisa como o trabalho será amplificado, e de acordo com seu público saberá de que maneira será desenvolvido este modelo de educação. Dessa forma, é importante ampliar as práticas interativas, conforme coloca Behar (2013, p. 46) com o foco na aprendizagem do aluno, sendo estas práticas fundamentadas em situações de aprendizagens desafiadoras e significativas.

Para tanto, cabe destacar que a EaD demanda objetivos pedagógicos diferenciados em relação ao ensino presencial, porém, com mais exigências. Oliveira (2003, p. 12) traz que o

Saberes Pedagógicos, Criciúma, v. 5, nº1, janeiro/abril 2021. - Curso de Pedagogia - UNESC 
que é válido no ensino presencial precisa ser estabelecido na modalidade de ensino a distância. Diante disso, Silva (2003, p. 400) destaca que:

[...] a partir de 20 de dezembro de 1996, com a lei 9.394 que fixa as Diretrizes e Bases da Educação a Distância passou a ser considerada alternativa regular e regulamentada de prestação educacional aos brasileiros. Hoje é uma estratégia de acesso à educação de qualidade, direito do cidadão e dever do Estado e da sociedade, que os textos legais e as normas oficiais passam a tratar.

Sob o ponto de vista de Silva (2003, p. 401), a EaD deixa de pertencer apenas a projetos e a partir da data mencionada começa a se concretizar, passando a oficializar-se, prestando o ensino superior educacional ao cidadão brasileiro. Este modelo que trata a LDB (Lei de Diretrizes e Bases da Educação) passa a ser uma educação de direitos e deveres ao Estado democrático.

De acordo com os embasamentos deste estudo, a Educação a Distância no Brasil já é legitimada, conforme destaca Silva (2003), Oliveira (2003) e Behar (2013) quando apontam que a Educação a Distância no Brasil passa por um processo de transformação bastante significativo no marco educacional, transformações para uma educação que passa a ser regular e oficial na história. Diante desta ideia, faz-se necessário destacar que como em qualquer educação, segundo Silva (2003, p. 398), a EaD sem dúvida necessita de profissionais capacitados para desenvolver e elaborar o ensino conforme a instituição deseja.

\section{MATERIAL DIDÁTICO DIGITAL}

O material didático digital tem como objetivo desenvolver e garantir a interatividade do aluno no seu processo de ensino-aprendizagem. Com isso, é importante que a elaboração desse material didático tenha sempre uma intencionalidade, ou seja, que este material tenha um objetivo específico para o educando, que é a aprendizagem.

Segundo Belisário (2003, p. 138), o material didático precisa ter um intuito no qual o professor leve o aluno à construção de conhecimentos. Por isso, visto que a pesquisa se apresenta a partir da análise do material didático digital na Educação a Distância, percebe-se 
então que o papel do material didático é que na ausência do professor este consiga contribuir com a aprendizagem do aluno.

Além disso, Belisário (2003, p. 139) destaca ainda que um grande desafio de estudar a distância é ter que superar o isolamento das atividades educativas. Por este motivo, é fundamental que os meios de comunicação para o desenvolvimento de uma prática educativa contenham aulas bem planejadas e estruturadas. Assim, facilitar o avanço dos alunos nas práticas educativas.

O material didático digital é um instrumento que busca a aprendizagem, e que por sua finalidade é utilizado um ou mais recursos digitais para a sua construção. Os materiais mais utilizados nos tempos atuais são: as páginas da Web, Blogs, wikis e os softwares no campo educacional, e também podemos citar os objetos de aprendizagem. Ao se referir a esses recursos pedagógicos, Behar (2013,p. 239) comenta que:

\begin{abstract}
A página web (site) pode ser publicada na internet da instituição [...] pode permitir aos alunos o acesso a várias fontes de informações [...] o site pode disponibilizar links para a página web de cada aluno, pode ainda conter animações e simulações interativas. [...] possibilita um apoio pedagógico que não se limita à duração de uma determinada aula. [...] A utilização do blog permite não apenas a comunicação de uma informação, pode ser construída em conjunto a professores e alunos. [...] os wikis permitem a construção de documentos de maneira colaborativa, que permite a criação e edição de textos existentes. [...] O software é todo programa de computador voltado ao processo de ensino aprendizagem.
\end{abstract}

Diante desta análise, conseguimos perceber que os Materiais Didáticos Digitais propiciam a interação entre professor e aluno. E, conforme Behar (2013, p. 243), esses materiais quando utilizados com alguma intencionalidade conseguem ultrapassar as barreiras das salas de aula, ou seja, são instrumentos utilizados no campo educacional e fora também.

Por isso, quando se trata de Materiais Didáticos Digitaos fala-se de instrumentos que no ponto de vista de Behar (2013, p. 245) envolvem o levantamento da construção dos materiais, destacando-se a relevância das características interdisciplinares. Com esses aspectos o professor poderá desenvolver com os alunos o envolvimento de seus conhecimentos, habilidades e atitudes diante desta era digital. De acordo com Behar (2013, p. 45): 
As disciplinas podem exigir do uso de ambientes virtuais de aprendizagem (AVA), blogs, Objetos de Aprendizagem (AO), entre outros, que precisam ser conhecidos, ou no momento introdutório do curso ou quando deles se fizer uso durante o curso. A estrutura em termos de tutoria é de fundamental importância para a organização das atividades para que o aluno tenha segurança quanto ao suporte que terá ao longo da formação.

O suporte que o aluno precisa ter durante sua formação, conforme Behar (2013, p. 45), é em relação ao desenvolvimento das disciplinas, destacando que este contexto implicará no processo de formação do aluno. A instituição precisa promover todo Objeto de Aprendizagem necessário para o andamento das propostas de atividades, e, além disso, o aluno precisa se sentir seguro com relação aos requisitos que exige a instituição de ensino.

Assim, no olhar de Behar (2013, p. 46), o desenvolvimento do processo de interação pode ser realizado pelos ambientes virtuais, bem como webconferência e videoconferência. Entretanto, são diversos os ambientes virtuais que a EAD dispõe para o processo de ensinoaprendizagem. Além dessas propostas de aprendizagens virtuais, Behar (2013, p. 47) destaca ainda que para ter acesso nesses ambientes os alunos da EAD podem fazer uso acessando as vias web, por algum instrumento que seja conectado à internet. Esses recursos que a autora destaca podem ser notebooks, tablets e celulares.

Mediante esse cenário em que se encontra a educação, com diversos recursos tecnológicos, o Objeto de Aprendizagem (OA), de acordo com Behar (2013, p. 48), é todo elemento que pode auxiliar na construção do conhecimento e da aprendizagem, interagindo com o aluno. Isso traz uma aprendizagem significativa, pois se trata de um OA que por sua vez pode ser utilizado em qualquer disciplina, tornando-o interdisciplinar. Um ponto relevante é a necessidade de ser utilizado em diversos conteúdos.

Na visão de Behar (2013, p. 48), o Objeto de Aprendizagem vem sendo um material educacional importante e por este motivo é um dos mais citados no presente momento. Uma importante característica de um OA é que os alunos têm acesso a várias fontes de informações para abordar diferentes pontos de vista em relação à aprendizagem. Portanto, Behar (2013, p. 50) traz o Objeto de Aprendizagem como um recurso em que o aluno pode criar seu próprio método para aplicar nas suas atividades de interação, individual ou coletivo. 


\section{MATERIAL DIDÁTICO DIGITAL NA DISCIPLINA DE METODOLOGIA CIENTÍFICA E DA PESQUISA DA UNESC}

A Educação a Distância aparece no contexto da educação por meio de inúmeras formas, e sabemos que ainda existem críticas no que diz respeito a este modelo de educação. Para tanto, apresenta-se neste contexto a experiência de uma disciplina a distância em uma universidade comunitária. A disciplina de Metodologia Científica e da Pesquisa (MCP), conforme Giacomazzo et al. (2018, p. 4), foi uma decisão da reitoria como um projeto institucional.

Com isso, a implementação da disciplina aconteceu no primeiro semestre de 2017. Conforme Giacomazzo et al. (2018, p. 5), para a organização da disciplina foram convidados professores com experiência para que organizassem o plano de ensino. Nesse sentido, uma mudança significativa inicia na instituição, pois começa um novo olhar pedagógico em relação às discussões e planejamentos das aulas. Como coloca Behar (2008, p. 126), a modalidade de ensino a distância no seu contexto não permite improvisos, é importante que haja antecipadamente um planejamento dos instrumentos utilizados.

Partindo desse pressuposto, nos materiais didáticos digitais da disciplina de MCP a distância faz-se necessário destacar a estrutura do Ambiente Virtual de Aprendizagem - moodle -, um dos instrumentos utilizados pelos acadêmicos para a realização de propostas de atividades educativas. Nesse ambiente de aprendizagem são disponibilizadas as atividades para os acadêmicos. Conforme Giacomazzo et al. (2018, p. 11):

[...] a estrutura do moodle conta com informações gerais, como a apresentação da disciplina, fórum de notícias, um cronograma e documentos informativos (sistema de notas e mídias, plano de ensino. [...] artigos, textos, recursos de apoio, música, vídeos, aulas comentadas). $\mathrm{E}$ as atividades propostas, fóruns quiz e postagem de trabalhos diversos.

Com isso, percebe-se que as aulas de MCP apresentam diferentes materiais didáticos digitais que contribuem para o processo de aprendizagem do aluno. O estudante da Educação a Distância necessita de uma aprendizagem interativa e significativa, para que seus momentos de aprendizagem não se tornem monótonos. Segundo Belisário (2003, p. 143), os

Saberes Pedagógicos, Criciúma, v. 5, nº1, janeiro/abril 2021. - Curso de Pedagogia - UNESC 


\section{SABERES PEDAGÓGICOS \\ Revista do Curso de Graduaçào de Pedagogia - Unesc \\ ISSN 2526-4559}

momentos de estudos dos alunos da EaD são diferenciados dos alunos do ensino presencial. Portanto, é fundamental que as aulas e os materiais didáticos digitais disponibilizados se tornem significativos em relação à aprendizagem do sujeito.

Tendo em vista essas questões, a plataforma ainda disponibiliza, segundo Giacomazzo et al. (2018, p. 11), os relatórios de notas que servem tanto para o professor como para o acadêmico. Portanto, no que diz respeito aos materiais didáticos da disciplina de MCP na modalidade a distância nos cursos presenciais percebe-se integração e envolvimento dos docentes, haja vista que eles são mediadores do conhecimento de cada acadêmico.

Portanto, as propostas de atividades dos alunos nesta modalidade de ensino são consideradas atividades em que o professor como mediador da aprendizagem avalia como está sendo o desenvolvimento de cada aluno. É a partir das atividades propostas que o docente pode saber como está sendo a interatividade entre os alunos e as atividades estabelecidas no ambiente de aprendizagem.

\section{METODOLOGIA, APRESENTAÇÃO E ANÁLISE DE DADOS}

A pesquisa segue uma abordagem quanti-qualitativa, pois traz questões fechadas e abertas em seu instrumento de coleta dos dados. Contudo, focaliza-se na abordagem qualitativa para suas análises, pois busca investigar os objetivos apresentados para a realização da reflexão entre teoria e prática. Além disso, segundo Ludke e André (1998), a pesquisa qualitativa é uma aproximação extensa, adequada para se ter a compreensão do que o pesquisador deseja pesquisar tendo como partida os pressupostos teóricos e práticos, visando aos aspectos para o conhecimento científico. Conforme Minayo (1999, p. 134):

\footnotetext{
A pesquisa qualitativa torna-se importante para [...] compreender os valores culturais e as representações de determinado grupo sobre temas específicos [...] para compreender as relações que se dão entre atores sociais tanto no âmbito das instituições como dos movimentos sociais [...] para avaliação das políticas públicas e sociais tantos do ponto de vista de sua formulação, aplicação técnica, como dos usuários a quem se destina.
}

A pesquisa é direcionada pelos objetivos propostos, como por exemplo pesquisar os materiais didáticos disponíveis na disciplina de Metodologia Científica e da Pesquisa (MCP).

Saberes Pedagógicos, Criciúma, v. 5, nº1, janeiro/abril 2021. - Curso de Pedagogia - UNESC 


\section{SABERES PEDAGÓGICOS}

Revista do Curso de Graduaçào de Pedagogia - Unesc

ISSN 2526-4559

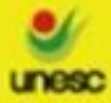

Diante disso, este estudo investiga sobre alguns Materiais Didáticos Digitais na disciplina de Metodologia Científica e da Pesquisa (MCP) na modalidade de Ensino a Distância na Universidade do Extremo Sul Catarinense (UNESC), selecionados até a semana 6 (semana que realizou-se a pesquisa por meio de um questionário no AVA) de 18 semanas. Trata-se de uma pesquisa de campo quanti-qualitativo, em que foram coletados dados por meio de um questionário, disponibilizado no AVA para acadêmicos em nove salas virtuais da disciplina de MCP em 2019/01, sem a identificação dos participantes, conforme tabela com o código da disciplina e o número de alunos, totalizando 145 respondentes.

\begin{tabular}{|l|l|l|l|l|l|l|l|l|l|}
\hline $17115-$ & $19113-$ & $17209-$ & $20411-$ & $16142-$ & $16437-$ & $22774-$ & $17761-$ & $11146-$ & Total = \\
20 & 6 & 45 & 17 & 2 & 13 & 9 & 18 & 15 & 145 \\
\hline
\end{tabular}

\subsection{Análise dos dados}

A análise dos dados está organizada partindo dos materiais selecionados da disciplina a distância Metodologia Científica e da Pesquisa (MCP) dos cursos de Graduação da Universidade do Extremo Sul Catarinense (UNESC) em 2019/01, que são: Material didático 01 - vídeo de apresentação da Biblioteca Eurico Back da UNESC; Material didático 02 - AULAS COMENTADAS Semanas 2, 3, 4, 5, 6; Material didático 03 - tutorial - Trabalhos Acadêmicos (TAC); Material didático 04 - filmes "UM CONTO SOBRE O PLÁGIO” e "O FÍSICO”; Material didático 05 - Livro da disciplina: organização dos capítulos e elementos da diagramação. Registra-se que os alunos poderiam ou não comentar suas respostas. Sendo 145 respondentes optou-se em não identificar e ou enumerar os respondentes, mas selecionar as respostas que melhor colaboram para significar as maiores opções.

\subsubsection{Material Didático 01 - Vídeo de apresentação da biblioteca Eurico Back da UNESC}

Este vídeo (5’38') integra os materiais didáticos da Semana 1, que aborda a história da universidade e, especificamente, da UNESC. Apresenta-se o vídeo institucional da Biblioteca Prof. Dr. Eurico Back. De acordo com o roteiro de estudos, ao final desta primeira 


\section{SABERES PEDAGÓGICOS}

Revista do Curso de Graduaçào de Pedagogia - Unesc

ISSN 2526.4559

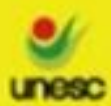

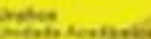

semana de estudos o aluno deve compreender entre outros aspectos o funcionamento da Biblioteca.

\section{Figura 1: Vídeo Semana 1 da Disciplina de MCP da UNESC}

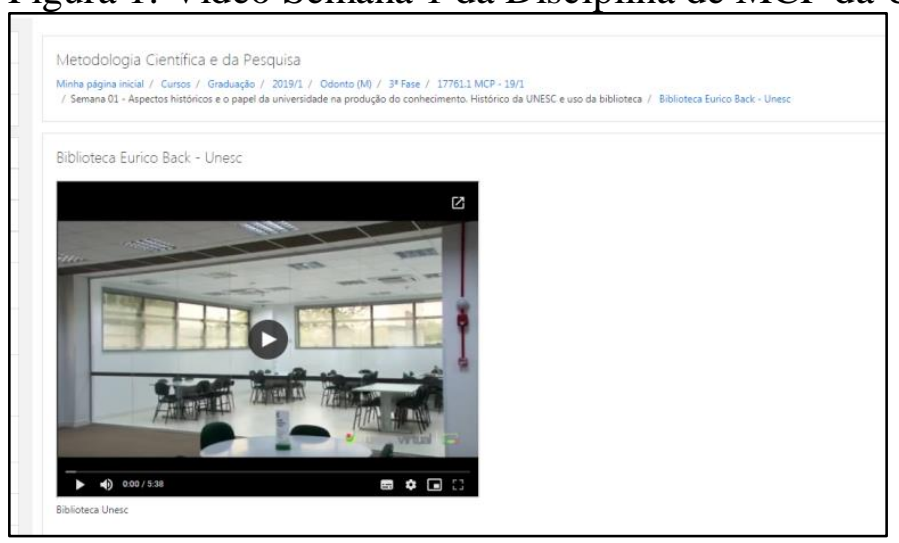

Fonte: AVA Unesc (2019).

Sobre este material didático os respondentes da pesquisa consideraram suficientes ${ }^{3}$ os seguintes aspectos, conforme o gráfico a seguir:

Gráfico 01: Avaliação do vídeo apresentação da Biblioteca Eurico Back da UNESC

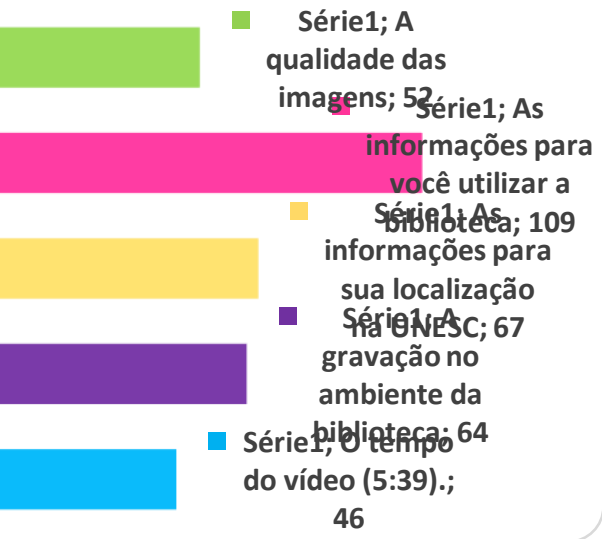

Fonte: Elaborado pela autora (2019).

Na questão referente a este vídeo, os participantes poderiam escolher mais de uma opção de resposta. Sendo assim, observa-se, conforme o gráfico, que a maior opção evidencia

\footnotetext{
${ }^{3}$ Suficiente nesta pesquisa significa Excelente sobre o material didático avaliado.

Saberes Pedagógicos, Criciúma, v. 5, nº1, janeiro/abril 2021. - Curso de Pedagogia - UNESC
} 
que o vídeo cumpre seu objetivo, pois os respondentes consideraram que as informações para compreender o funcionamento da biblioteca foram suficientes. No geral todos os itens foram bem avaliados, sendo que o tempo do vídeo foi o que recebeu menor atribuição. Em relação às opções ao serem convidados a comentar as respostas, destacamos as seguintes respostas que exemplificam o que dizem os alunos sobre os elementos investigados neste vídeo:

Foi uma atividade bastante importante e de grande auxílio para nós alunos, eu não sabia como funcionava a biblioteca, o vídeo me ajudou muito.

Todas as opções acima foram importantes, pois colaboraram para que os alunos se familiarizassem mais com a biblioteca da Universidade.

As imagens são ótimas, a explicação sobre como usar a biblioteca é direta, assim fica muito fácil para compreender, o tempo de vídeo foi suficiente para entender a regras do local.

Conforme Belisário (2003, p. 142), os vídeos podem ser fundamentais para os alunos, tornando o estudo mais dinâmico quando é quebrada a monotonia de apenas leituras. Diante disso, o vídeo exemplifica os textos de uma forma interativa, garantindo uma aprendizagem lúdica para o acadêmico. Em relação ao tempo de gravação no ambiente da biblioteca, os alunos destacam:

O tempo é suficiente, uma vez que se pode explicar como funciona a biblioteca, sem se prolongar demasiadamente.

Tempo suficiente para entender o que está sendo mostrado e não é cansativo.

O tempo do vídeo curto é bom para quem não tem muito tempo e é melhor para prestar atenção, o ambiente e as imagens ajudam a entender melhor.

Percebemos nesta pergunta que o tempo de vídeos apresentados para os alunos da EaD é um ponto significativo, como mostram as respostas, por isso Mattar (2008, p. 112) destaca que o aluno da $\mathrm{EaD}$, devido às tecnologias, necessita interagir com os materiais apresentados, bem como vídeos, textos, sons e outros recursos, portanto esses materiais precisam ter um tempo em que prenda a atenção do sujeito. Com isso, devido à realização das atividades interativas, como por exemplo o vídeo, o acadêmico acaba avançando uma etapa no seu processo de aprendizagem. E ainda por se tratar de um tempo que consideram suficientes para explicação, os alunos conseguem interagir com a temática estudada.

Saberes Pedagógicos, Criciúma, v. 5, nº1, janeiro/abril 2021. - Curso de Pedagogia - UNESC 


\subsubsection{Material Didático 02 - Aulas comentadas, semanas 2,3,4,5, e 6 .}

As aulas comentadas são vídeos que contêm uma apresentação em power point, algumas animações, frases, figuras, imagens e uma narração do professor. A seguir o gráfico das respostas, onde os alunos poderiam escolher o número de opções desejadas:

Gráfico 02: Avaliação Aulas Comentadas Semanas 2, 3, 4, 5, 6

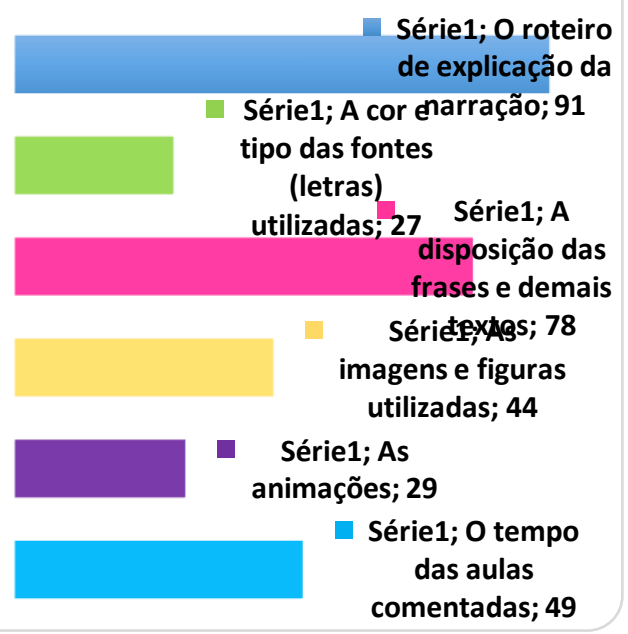

Fonte: Elaborado pela autora (2019).

De acordo com o gráfico, os elementos mais suficientes foram o roteiro de explicação da narração, que é elaborado pelo professor, e em segundo lugar a disposição das frases e demais textos. Entre os comentários desta questão, para compreender melhor os dados, destacamos estes:

O conjunto todo se torna importante, entre as aulas comentadas e os textos, muito esclarecidos. Também o conteúdo de cada semana, assim, dá para compreender bem a matéria.

"Com textos ou frases é mais fácil de saber o que a narradora está falando, pois se pode acompanhar, assim a explicação é melhor, é bem objetiva. É importante que se explique com textos e frases, mas também com imagens e figuras, pois assim prende o leitor e fica mais fácil de aprender."

Com isso, percebe-se a importância de um material didático bem planejado, organizado e elaborado na sua totalidade, ou seja, no conjunto, conforme mencionado por um Saberes Pedagógicos, Criciúma, v. 5, nº , janeiro/abril 2021. - Curso de Pedagogia - UNESC 
dos alunos, tendo como objetivo fim o processo de aprendizagem. Conforme Belisário (2003, p. 136), as aulas comentadas contribuem para desenvolver habilidades necessárias para o aprendizado a distância, bem como a interação entre o aluno e o material apresentado. Em outras palavras, aprendem melhor a refletir e a relacionar os conteúdos.

Todavia, destaca-se ainda a resposta significativa de um acadêmico quando afirma: "As atividades tiveram um ótimo apoio didático, onde ficou muito claro para entender, trazendo muito significado para mim". Diante disso, o cuidado didático na elaboração de um material para o aluno da EaD torna mais confiante o processo de aprendizagem, pois, como coloca Behar (2013), o desenvolvimento pedagógico precisa levar em conta as estratégias que permitem ao aluno aprender interagindo, pesquisando e organizando suas atividades. Portanto, percebe-se que as situações de aprendizagem desenvolvidas para os alunos, em relação ao material didático, possibilitam que suas habilidades sejam desenvolvidas no processo para além dos conteúdos.

\subsubsection{Material Didático 03 - Tutorial - Trabalhos Acadêmicos (TAC)}

O tutorial é um material didático disponível para que os alunos compreendam a elaboração de trabalhos acadêmicos dentro das normas da Associação Brasileira de Normas Técnicas (ABNT). Perguntou-se então se este era relevante. De acordo com as respostas, segue o gráfico:

Gráfico 03: Relevância do TAC

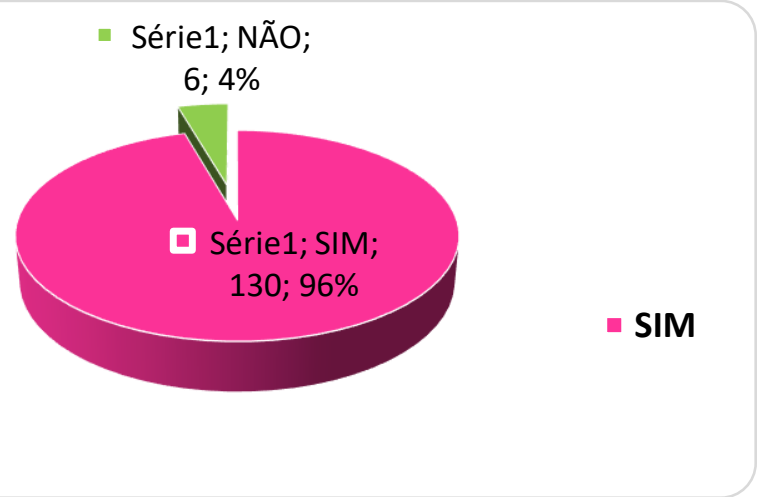

Fonte: Elaborado pela autora (2019)

Saberes Pedagógicos, Criciúma, v. 5, nº1, janeiro/abril 2021. - Curso de Pedagogia - UNESC 
Sendo assim, tem-se que a maioria dos 145 alunos respondentes, totalizando 130, considera relevante o material didático tutorial. Os tutoriais são modelos a seguir, que apresentam a forma e o formato que orienta a organização de um trabalho e ou atividade, considerado também como um exemplo. A seguir algumas respostas dos comentários sobre esta questão que na sua maioria afirmaram ser fundamental, importantíssimo, essencial. Eis os motivos:

Sim, pois o TAC facilita a elaboração da atividade e sabendo que somos neófitos acerca dos trabalhos acadêmicos, o tutorial explica de maneira simples, concisa e cativante.

É relevante sim, pois a maioria dos universitários que estão iniciando, estão vindo do ensino médio, e a elaboração de trabalhos de ensino médio e universidade é completamente diferente.

Porque contendo o tutorial fica bem detalhado como fazer os trabalhos, se caso não houvesse, seria insuficiente apenas os textos, com o tutorial, deu pra analisar muito bem como fazer os trabalhos acadêmicos.

O tutorial é de suma importância, uma vez que é algo bem didático e essencial para os estudantes que nunca desempenharam algo parecido no meio escolar.

De acordo com as respostas dos alunos, percebe-se que o tutorial para a elaboração de trabalhos acadêmicos é fundamental no decorrer do processo de formação. Muitos estudantes acham indispensáveis os exemplos que são disponibilizados no ambiente virtual de aprendizagem e até afirmam que sem esses exemplos seria "impossível” aprender apenas com leituras. Por isso, Belisário (2003, p. 142) destaca que os exemplos levados para os alunos referentes aos materiais didáticos precisam cumprir seu papel, quebrando uma rotina pesada de apenas teorias e partindo para a prática. No entanto, além de leituras que não deixam de ser significativas, o contato com os exemplos tutoriais também se mostram relevantes nesses aspectos.

\subsubsection{Material Didático 04 - Filmes "Um conto sobre o plágio" e "O físico".}

O material filme neste caso são produções cinematográficas e vídeos independentes, abertos, produzidos externamente, mas que podem ser utilizados para 
complementar os conteúdos e estão disponíveis na rede, internet e em canais de vídeos. Neste caso, perguntou-se se foram relevantes.

Gráfico 04: Relevância do material Filme para compreensão dos conteúdos

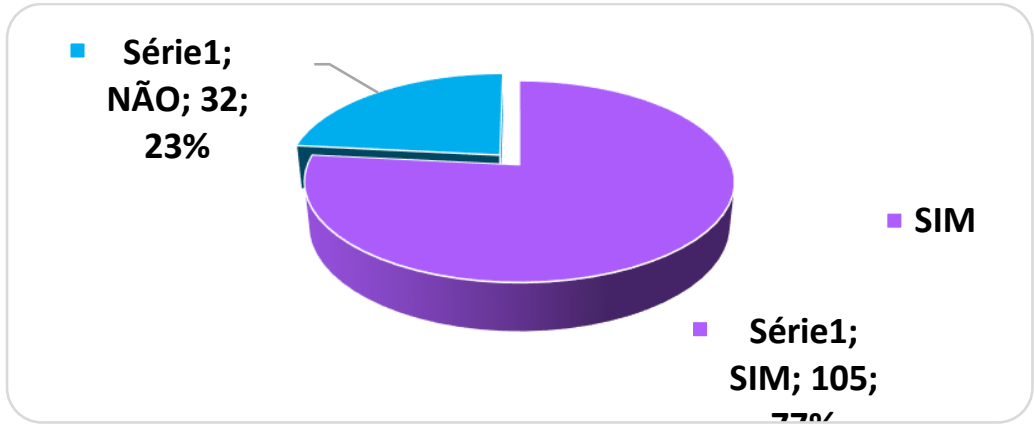

Fonte: Elaborado pela autora (2019).

Em relação ao filme apresentado em uma das semanas, os alunos demonstraram em suas respostas uma compreensão suficiente em relação aos conteúdos. Por isso destacamos esse material didático a ser utilizado como uma ferramenta de aprendizagem significativa. Belisário (2003, p. 140) comenta que o filme é um recurso dinâmico na construção desse processo que é a aprendizagem, e por este motivo o roteirista pode exemplificar um texto em um filme em que o aluno consiga compreender o conteúdo em 60 a 90 min. O filme, por sua vez, apresenta a interatividade com o aluno, prendendo mais a atenção dos telespectadores.

\subsubsection{Material Didático 05 - Livro da disciplina: Organização dos capítulos e elementos da diagramação.}

O livro da disciplina é um material elaborado por professoras da universidade, editado pelo Setor de Educação a Distância, que faz a revisão e diagramação. No questionário os alunos poderiam escolher as opções que consideravam mais suficientes sobre este material. As respostas foram: 
Gráfico 05: Avaliação do Livro da Disciplina de MCP
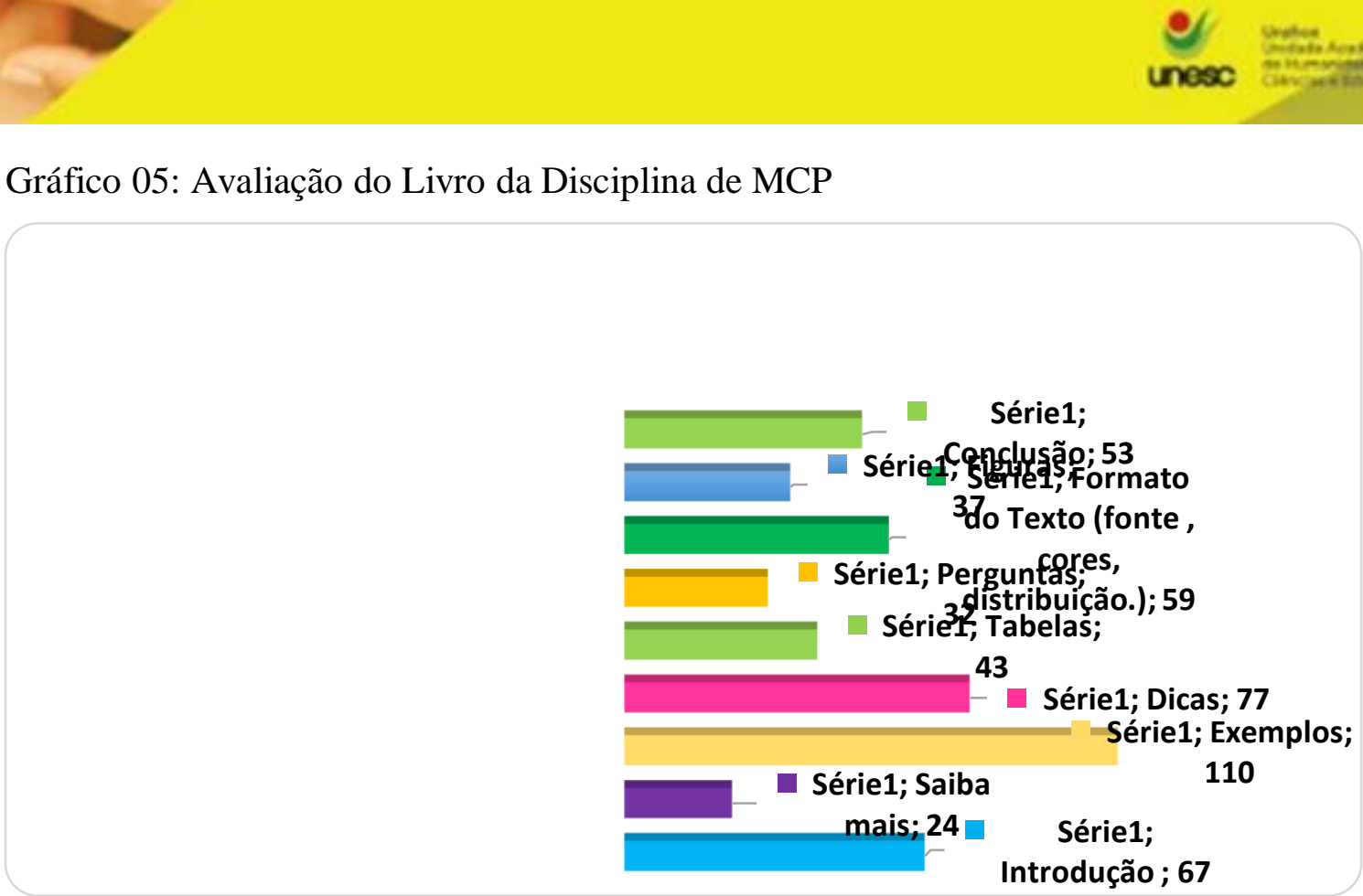

Fonte: Elaborado pela autora (2019).

Percebe-se que o elemento "exemplos" foi o mais selecionado, seguido do elemento "dicas" e "introdução". Sobre estes aspectos, ao comentarem suas respostas, destacamos:

As dicas por serem concisas contribuem efetivamente e como são acompanhadas por exemplos, facilitam ainda mais para que o entendimento seja rápido e eficaz.

É a partir da introdução que começa a apresentar o trabalho, no início do texto tem que estar presentes todas informações, por isso a introdução é importante.

O que foi muito importante para mim foram os exemplos, pois dessa forma conseguia responder as questões de forma mais segura.

Também é importante registrar que, não menos importantes, os demais elementos foram muito bem avaliados. Tem-se novamente que se deve preocupar com todos os aspectos desde a introdução até a conclusão. Um aluno destaca na sua resposta aberta que "tudo ajuda, pois são elementos importantes para que prenda o leitor e faça com que ele compreenda o texto ou o livro corretamente". De acordo com Belisário (2003, p. 138):

A importância do material didático nesse processo, no qual o professor passa a exercer o papel de condutor de um conjunto de atividades que procura levar à construção de conhecimentos; daí a necessidade de esse material apresentar-se numa linguagem dialógica que, na ausência física do professor, possa garantir um tom coloquial,

Saberes Pedagógicos, Criciúma, v. 5, nº1, janeiro/abril 2021. - Curso de Pedagogia - UNESC 
reproduzindo uma conversa entre professor e aluno, tornando sua leitura leve e motivadora.

Ler para ampliar o conhecimento é fundamental para o aluno, visto que ele não se encontra em um ritmo de estudo comparado ao ensino presencial. Por isso destaca-se a importância do material didático bem estruturado em relação ao material de leitura disponibilizado, leituras estas que apresentam tabelas, exemplos, dicas e figuras. Em outro momento um acadêmico destacou ainda que "os textos disponibilizados são bem elaborados com base nas teorias feitas, são dinâmicos e de fácil compreensão".

Para Belisário (2003, p. 139), as leituras realizadas pelos alunos devem promover a compreensão do que está escrito, por isso precisa ler para avaliar, para identificar o sentido do texto. Como coloca Behar (2013, p. 240), o material didático digital é considerado como todo material direcionado à aprendizagem do sujeito, por isso devemos pensar como planejar esse material que é indispensável no ensino a distância.

\subsubsection{Material Didático: Qual a opinião dos alunos no contexto geral}

Para finalizar, de forma geral pedimos que os alunos respondessem qual a sua opinião sobre os materiais didáticos utilizados na disciplina de MCP e que elaborassem uma resposta. Com isso, destacam-se as seguintes respostas:

\footnotetext{
Os materiais são extremamente bons, faz-se notável a preocupação de fazer com que a didática não seja maçante, o que torna a aprendizagem mais prazerosa e tranquila.

Os materiais são bastante explicativos, claros e objetivos. Há bastantes citações de exemplos, roteiro da semana, o que auxilia muito o estudante, já que, por ser uma disciplina EaD temos a necessidade desse passo a passo de cada tema tratado.

Para integrar os textos, temos os vídeos que nos apresentam o assunto de maneira mais simplificada. Consegui aprender com muita facilidade os assuntos propostos justamente pela qualidade do material a ser estudado.
}

Percebe-se aqui o significado que tem o material didático para o acadêmico do ensino a distância. Behar (2013, p. 238) destaca que neste contexto mostramos a importância que tem a elaboração do material didático, uma vez que proporciona ao aluno o conhecimento

Saberes Pedagógicos, Criciúma, v. 5, nº1, janeiro/abril 2021. - Curso de Pedagogia - UNESC 


\section{SABERES PEDAGÓGICOS}

Revista do Curso de Graduaçào de Pedagogia - Unesc

ISSN 2526-4559

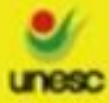

de habilidades. Por isso, o material didático acaba trazendo uma grande contribuição para essa modalidade de ensino, em que o aluno necessita ter autonomia e disciplina nos estudos.

Para tanto, identificamos ao longo da pesquisa a importância da interatividade no material didático, que por vezes é uma característica central de qualquer material. Do ponto de vista de Belisário (2003, p. 141), a interatividade é quando uma leitura realizada pelo aluno acontece de forma em que ele consiga interagir com o que está lendo e avança suas leituras na medida em que supera as fases do processo de ensino-aprendizagem. Portanto, é possível dizer que diante das respostas apresentadas e a partir dessa análise os materiais digitais estruturados e planejados auxiliam na formação integral do aluno.

Para finalizar a pesquisa, pedimos para que os alunos contribuíssem com suas opiniões referentes ao material didático da disciplina de MCP e, além disso, que elaborassem suas respostas. Poucos alunos destacaram alguns pontos negativos em relação ao material didático apresentado na disciplina, por isso não evidenciamos a minoria em nossas análises. Alguns alunos ressaltaram que os artigos são muito extensos e que demoram muito para ler. Em outras respostas, alguns alunos apontam que as aulas comentadas são "paradas" e que isso faz com que acabem perdendo o foco rápido.

Behar (2013, p. 100) coloca que é necessário sempre uma avaliação referente aos materiais apresentados aos alunos, pois o desenvolvimento se dá por meio das atividades propostas. Mediante esta reflexão, o desenvolvimento do aluno da EaD se dá a partir dos materiais didáticos, por isso uma avaliação dos alunos referente à metodologia das aulas preparadas pode ser significativa nesse processo, tendo em vista que os materiais didáticos e as aulas preparadas são direcionados para o desenvolvimento do aluno como um todo.

\section{CONCLUSÃO}

Com este trabalho foi possível perceber que a Educação a Distância no Brasil vem crescendo cada vez mais, e com o avanço das Tecnologias de Informação e Comunicação (TIC's) vem com o intuito de qualificar essa modalidade de ensino. Além disso, novas tecnologias foram criadas para que a educação fosse acessível para todo cidadão brasileiro. No 
entanto, a legislação vem se atualizando, para que a qualidade do ensino não seja comprometida.

Diante disso, os materiais didáticos digitais se tornam um aliado fundamental no processo de aprendizagem do aluno. Ao pesquisar sobre os materiais didáticos digitais disponíveis na disciplina de Metodologia Científica e da Pesquisa da UNESC, conseguimos evidenciar características desses materiais, a partir da preferência e percepção dos acadêmicos que podem colaborar para a elaboração de outros materiais no contexto da Educação a Distância.

Identificamos que o livro digital quando traz elementos de destaque e complementares, chamam mais atenção e tornam a leitura mais dinâmica. Também foi possível verificar que os audiovisuais, como aulas comentadas, vídeos apresentam um significado relevante ao processo de aprendizagem. Para que este processo de aprendizagem se concretize é importante que estes materiais disponibilizados sejam bem estruturados, designados ao perfil desse aluno. Como abordamos no decorrer da pesquisa, os alunos da Educação a Distância possuem tempo de estudo diferente dos alunos do ensino presencial.

Por fim, diante do perfil dos alunos da disciplina de MCP, e conforme suas concepções referentes ao material didático, percebemos que necessitam de materiais que prendam a sua atenção para que as aulas não fiquem monótonas. Por isso, o material didático se torna fundamental em relação à aprendizagem. Podemos dizer que o objetivo desta pesquisa foi alcançado quando analisamos quais são as características dos materiais didáticos digitais da disciplina de MCP são de preferências dos alunos. Por isso, o material didático digital na sua construção precisa ser pensado para o aluno que na ausência do professor consiga interagir com o mesmo.

\section{REFERÊNCIAS}

ALVES, João Roberto Moreira. A história da EaD no Brasil. In: LITTO, Fredrick M; FORMIGA, Marcos (org). Educação a Distância: O estado da arte. 1 ed. São Paulo, 2009.p. 9-13. 


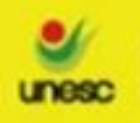

BEHAR, Patrícia Alejandra, et.al. Educação a distância e competências: uma articulação necessária. In: BEHAR, Patrícia Alejandra (org.). Competências em educação a distância. 1.ed. São Paulo: Penso, 2013. p. 37-240.

BELISÁRIO, Aluízio. O material didático na Educação a Distância e a constituição de propostas interativas. In: SILVA, Marcos (org.). Educação online: teorias, práticas, legislação e formação corporativa. $1^{\circ}$. ed. São Paulo: Loyola, 2003. p. 136 -146.

CRUZ, Dulce Maria. Aprendizagem por videoconferência. In: LITTO, Fredrick M;

FORMIGA, Marcos (org). Educação a distância: O estado da arte. 1 ed. São Paulo.2008. 8793.

GIACOMAZZO, Graziela. F. et al. Disciplina institucional a distância: processo de implantação numa universidade comunitária. Inter Saberes Revista Científica, v. 13, n. 29, p. 11, 2018. Disponível em:

https://www.uninter.com/intersaberes/index.php/revista/article/view/1415/414224 Acesso 10 de maio de 2019.

LUDKE, Menga; ANDRÉ, Marli. Pesquisa em educação: abordagens qualitativas. São Paulo: EPU, 1986.

MATTAR, João. Interatividade e aprendizagem. In. LITTO, Fredric M; FORMIGA, Marcos (org.). Educação a Distância. 1 ${ }^{a}$. ed. São Paulo: Abed, 2008. p. 112 - 117.

MINAYO, Maria Cecília de Souza. O desafio do conhecimento. 6. ed. São Paulo: Abrasco, 1999.

TORREZZAN, Cristina Alba Wildt; BEHAR, Patrícia Alejandra. Competências para a construção de materiais educacionais digitais baseados no design pedagógico. In: BEHAR, Patrícia Alejandra (org.). Competências em educação a distância. 1.ed. São Paulo: Penso, 2013. p. 237-262.

OLIVEIRA, Guimarães Elsa. Educação a Distância na transição paradigmática. São Paulo. Ed: Papirus, 2003. p. 12.

SILVA Neto, Francisco José. Legislação específica. In: SILVA, Marcos. (Org). Educação online: teorias, práticas, legislação e formação corporativa. 2.ed. São Paulo: Loyola, 2003. p. $400-434$.

UNESC. Relatório da comissão própria. CPA. Criciúma: CPA/SEAI. 2018. 
ZANETTE, Elisa Netto, et al. Educação a distância no ensino superior: a experiência de uma equipe multidisciplinar. In: ZANETTE, Elisa Netto; Giacomazzo Graziela Fátima; FIUZA, Patrícia Jantsch (org.). Tecnologias e inovação nas práticas pedagógicas: Trajetórias e Experiências. ed. Jundiaí: Paco. 2012. p. 13-23. 